\title{
Surgical pulmonary valve replacement: A benchmark for outcomes comparisons
}

\author{
E. Dean McKenzie, MD, ${ }^{\mathrm{a}, \mathrm{b}}$ Muhammad S. Khan, MD, ${ }^{\mathrm{a}, \mathrm{b}}$ Thomas W. Dietzman, BS, ${ }^{\mathrm{b}}$ \\ Francisco A. Guzmán-Pruneda, MD, ${ }^{\mathrm{a}, \mathrm{b}}$ Andres X. Samayoa, MD, ${ }^{\mathrm{a}, \mathrm{b}}$ Aimee Liou, MD, \\ Jeffrey S. Heinle, MD, ${ }^{\mathrm{a}, \mathrm{b}}$ and Charles D. Fraser, Jr, MD ${ }^{\mathrm{a}, \mathrm{b}}$
}

\begin{abstract}
Background: Patients with right heart obstructive lesions develop residual or recurrent right ventricle outflow tract pathology as a result of native or implanted pulmonary valve (PV) dysfunction. Until recently, the standard of care has been surgical placement of a PV or valved right ventricle to pulmonary artery conduit. Catheter-based options are being increasingly applied in patients with PV dysfunction. The purpose of our study was to evaluate outcomes of surgical pulmonary valve/conduit replacement (PVR) at a large pediatric hospital to provide contemporary benchmark data for comparison with developing technologies.
\end{abstract}

\begin{abstract}
Methods: Retrospective review of patients undergoing PVR not associated with complex concomitant procedures from July 1995 to December 2010 was completed. Inclusion criteria were designed to generally match those applied to patients promoted for catheter-based valve replacement based on age and weight (age $\geq 5$ years and weight $\geq 30 \mathrm{~kg}$ ).

Results: There were 148 PVRs with all patients having undergone $\geq 1$ previous interventions (tetralogy of Fallot [53\%] and pulmonary atresia [17\%]). Surgical indications were PV insufficiency (60\%), PV stenosis (26\%), and both $(13 \%)$. Valves used included bioprosthetic $(n=108 ; 73 \%)$ and homografts $(n=40 ; 27 \%)$. Timeto-extubation, intensive care unit stay, and hospital length of stay were $<1$ day (interquartile range, $0-1$ day), 2 days (interquartile range, 1-2 days), and 5 days (interquartile range, 4-6 days), respectively, with no hospital deaths. Freedom from PV reintervention at 1, 3, and 5 years was $99 \%, 99 \%$, and $94 \%$, respectively. Multivariable analysis showed age $<13$ years $(P=.003)$, and smaller valve size $(P=.025)$ were associated with increased risk of valve reintervention. Patient survival at follow-up (mean, $5.0 \pm 3.9$ years) was 99\%.
\end{abstract}

Conclusions: Surgical PVR is safe with low in-hospital and midterm follow-up mortality and reoperation rates. These outcomes provide a useful benchmark for treatment strategy comparisons. (J Thorac Cardiovasc Surg 2014; 148:1450-3)

Most patients born with right heart obstructive lesions develop residual or recurrent right ventricle (RV) outflow tract pathology as a result of native or implanted pulmonary valve $(\mathrm{PV})$ dysfunction. When intervention is required, the standard of care has been surgical placement of a competent $\mathrm{PV}$ or valved RV to pulmonary artery conduit. Recently, percutaneous pulmonary valve (PPV) placement has become a viable therapeutic alternative in selected patients when intervention is necessary. ${ }^{1}$ Advocates of PPV placement justify the use of this novel but unproven therapy

From the Michael E. DeBakey Department of Surgery, ${ }^{\text {a }}$ Baylor College of Medicine, Houston, Tex; Department of Congenital Heart Surgery, ${ }^{\mathrm{b}}$ Texas Children's Hospital, Houston, Tex; and Department of Pediatric Cardiology, ${ }^{\mathrm{c}}$ Baylor College of Medicine and Texas Children's Hospital, Houston, Tex.

Disclosures: Authors have nothing to disclose with regard to commercial support.

Received for publication May 15, 2013; revisions received Feb 12, 2014; accepted for publication Feb 21, 2014; available ahead of print April 2, 2014.

Address for reprints: E. Dean McKenzie, MD, Department of Congenital Heart Surgery, Texas Children's Hospital, 6621 Fannin St, WT19345H, Houston, TX 77030 (E-mail: edmckenz@texaschildrens.org).

$0022-5223 / \$ 36.00$

Copyright (c) 2014 by The American Association for Thoracic Surgery

http://dx.doi.org/10.1016/j.jtcvs.2014.02.060 because it is less invasive. It is not clear that PPV placement is safer or more effective than surgical PV placement. Advocates of PPV placement and the patients offered this alternative need current outcome data for surgical PV replacement (PVR) so that informed decisions may be made when both percutaneous and surgical options are available.

\section{METHODS}

This was a retrospective review of all patients who underwent a surgical PVR without concomitant complex cardiac procedure at Texas Children's Hospital from June 1995 to December 2010. Institutional review board approval from the Baylor College of Medicine was obtained for conducting this study.

\section{Study Groups}

We conducted an analysis of patients who matched the age and weight criteria for catheter-based valve replacement, as per an earlier published report $^{1}$; that is, aged $\geq 5$ years and weight $\geq 30 \mathrm{~kg}$ at the time surgical PVR was completed.

\section{Outcomes and Data Collection}

The primary outcome was patient survival. Freedom from reintervention of the replaced valve was also measured as a secondary outcome. 


\section{Abbreviations and Acronyms \\ $\mathrm{PPV}=$ percutaneous pulmonary valve \\ $\mathrm{PV}=$ pulmonary valve \\ $\mathrm{PVR}=$ pulmonary valve replacement \\ $\mathrm{RV}=$ right ventricle}

concomitant procedures included main or branch PA reconstruction in 62 patients $(42 \%)$, RV or RV outflow tract reconstruction in 32 patients $(22 \%)$, and atrial septal defect/ventricular septal defect/patent ductus arteriosus closure in 12 patients $(8 \%)$. Aortic crossclamping and myocardial arrest was only used when a residual intracardiac shunt was identified. Forty-one of 148 patients $(28 \%)$ received an average of $1.9 \pm 1$ of the following products during their admission (includes inside and outside of the odds ratio): red blood cells, fresh frozen plasma, platelets, or cryoprecipitate. Of these 41 patients, $17(42 \%)$ received red blood cells and/or platelets intraoperatively. None had transfusion reactions. All patients had $\geq 1$ previous interventions with most common fundamental diagnosis of tetralogy of Fallot $(\mathrm{n}=79 ; 53 \%)$. Valves used included 108 bioprosthetic valves $(73 \%) \quad(n=39$ Carpentier-Edward Perimount [Edwards Lifesciences, Irvine, Calif], $\mathrm{n}=33$ Medtronic Hancock [Medtronic Inc, Minneapolis, Minn], $\mathrm{n}=18$ Medtronic Contegra [Medtronic Inc], $\mathrm{n}=17 \mathrm{St}$ Jude Medical Epic [St Jude Medical Inc, St Paul, Minn], and $\mathrm{n}=1$ Medtronic Freestyle [Medtronic, Inc]) and 40 homografts (27\%) (Table 1).

\section{Hospital Course, Outcomes at Follow-up, and Risk Factors for Reintervention}

The median ventilator support was $<1$ day (IQR, 0-1 days), median intensive care unit stay was 2 days (IQR, 1-2 days), whereas median hospital length of stay was 5 days (IQR, 4-6 days). There was 1 reexploration secondary to mediastinal hematoma $(0.7 \%)$ but no active bleeding was identified. There were no other major complications during the hospital stay. The hospital survival was $100 \%$. Freedom from PV reintervention at 1, 3, and 5 years was $99 \%, 99 \%$, and $94 \%$ (Figure 1). Multivariable analysis showed that age younger than 13 years at surgery $(P=.003)$ and small valve size $(P=.025)$ were associated with increased risk of valve reintervention (Table 2). There were 2 deaths on follow-up after 2 years and after 11 years of noncomplex surgical PVR. One patient died secondary to severe cardiac dysfunction and 1 patient developed respiratory tract infection leading to respiratory failure and death. Patient survival at a mean follow-up of $5.0 \pm 3.9$ years in this cohort was $99 \%$.

\section{DISCUSSION}

With growing experience with PPV placement, our goal was to describe a contemporary experience with surgical PVR in a patient population comparable to candidates for the percutaneous approach. If interventional cardiologists and patients are to make well-informed decisions regarding PPV placement, the alternative surgical approach must be understood. Although less invasive procedures are attractive to both patients and physicians, they only benefit a patient if they achieve a result comparable with the more invasive procedure without increased risk. The early

\section{Analysis of Patients Eligible for PPV Who Underwent Surgical PVR}

There were 148 PVRs in 143 patients who matched the age and weight criteria for PPV. The most common 
TABLE 1. Characteristics of all patients and the study population who underwent surgical pulmonary valve replacement

\begin{tabular}{lcc}
\hline \multicolumn{1}{c}{ Characteristic } & $\begin{array}{c}\text { All patients } \\
(\mathbf{n}=\mathbf{2 4 7})\end{array}$ & $\begin{array}{c}\text { Study } \\
\text { population } \\
(\mathbf{n}=\mathbf{1 4 8})\end{array}$ \\
\hline Median age, y & $12.6(6.6-17.1)$ & $15.9(13.6-19.6)$ \\
Median weight, kg & $40.2(18.8-57.8)$ & $55.3(43.5-66.6)$ \\
Female & $99(40)$ & $55(37)$ \\
Diagnosis & $103(42)$ & $79(53)$ \\
$\quad$ Tetralogy of Fallot & $53(21)$ & $25(17)$ \\
$\quad$ Pulmonary atresia & $33(13)$ & - \\
$\quad$ Truncus arteriosus & - & $13(9)$ \\
$\quad$ Transposition of great arteries & $89(60)$ & $123(50)$ \\
Indication for surgery & $39(26)$ & $80(33)$ \\
$\quad$ Regurgitation & $19(13)$ & $38(15)$ \\
$\quad$ Stenosis & $22(14-33)$ & $23(18-33)$ \\
$\quad$ Both & $120 \pm 50$ & $121 \pm 51$ \\
Median valve size (mm) & & \\
Mean cardiopulmonary bypass & $1(0-1)$ & $<1(0-1)$ \\
$\quad$ time, min & $2(1-2)$ & $2(1-2)$ \\
Median ventilator support time, d & & \\
Median duration of intensive care & & $5(4-6)$ \\
$\quad$ unit stay, d & & $148(100)$ \\
Median duration of hospital stay, d & $5(4-6)$ & \\
Hospital survival & $246(99.6)$ & \\
\hline
\end{tabular}

Values are given as median (interquartile range), $\mathrm{n}(\%)$, or mean \pm standard deviation.

hemodynamic performance of the percutaneously placed valve has been good and probably similar to surgical PVR, but this is not known. The average sizing balloon diameter of the first 124 patients in the Melody valve trial $^{2}$ was $17 \mathrm{~mm}$, whereas the median valve size in our surgical series was $23 \mathrm{~mm}$ (range, 18-33 mm). In their description of the short and midterm outcomes in the expanded Melody

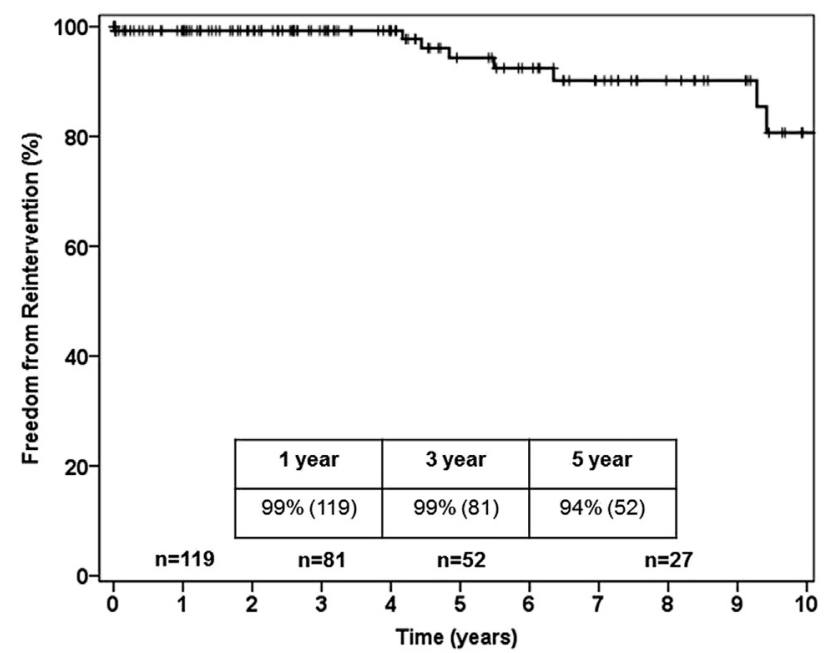

FIGURE 1. Freedom from reintervention for patients eligible for percutaneous intervention who underwent surgical pulmonary valve replacement (PVR).
TABLE 2. Multivariable analysis for risk factors of valve failure in patients eligible for percutaneous intervention who underwent surgical pulmonary valve replacement (PVR)

\begin{tabular}{lcccc}
\hline & & & \multicolumn{2}{c}{$\mathbf{9 5 \%}$ Confidence interval } \\
\cline { 3 - 5 } \multicolumn{1}{c}{ Variable } & $\boldsymbol{P}$ value & Odds ratio & Lower & Upper \\
\hline Age $<13$ y & .003 & 6.433 & 1.849 & 22.385 \\
Tetralogy of Fallot & .137 & 3.92 & 0.648 & 23.73 \\
Pulmonary atresia & .645 & 1.541 & 0.233 & 10.188 \\
Smaller valve size & .025 & 1.449 & 1.047 & 2.004 \\
Homograft & .737 & 1.235 & 0.360 & 4.240 \\
Stenosis & .462 & 0.556 & 0.117 & 2.652 \\
\hline
\end{tabular}

valve trial, ${ }^{2}$ the investigators suggest that earlier intervention may be justified and by decreasing the number of heart procedures and minimizing the duration of $\mathrm{RV}$ pressure and volume overload, the risk-benefit balance may be shifted. It is not clear that earlier intervention is justified when PPV placement does not definitely offer increased safety or effectiveness profiles. Prior sternotomy does not increase the risk in pediatric cardiac surgery. ${ }^{3}$ If reoperations involving stented branch pulmonary arteries can be considered analogous, having multiple stents within the RV outflow tract will increase the complexity and length of future surgical procedures after PPV placement. Prior stenting of the RV outflow tract associated with the percutaneous approach will alter future surgical options, perhaps decreasing the possibility of simple valve insertion.

Although related to the limitations of current technology, stent fractures of percutaneously placed valves are common and lead to early valve failure. ${ }^{4}$ Freedom from reintervention after PPV placement is $86 \%$ at 27 months and predicted to be $53 \%$ at 5 years. ${ }^{5}$ In contrast, our 5-year freedom from redo-PVR was $6 \%$, a result that parallels other published series with comparable study populations (Table 3). ${ }^{6-14}$

Despite longer hospitalization and increased need for blood transfusion with surgical PVR, PPV is more costly. ${ }^{5}$ Notably, no patient in the surgical PVR cohort in our series underwent a nontherapeutic procedure, whereas procedural failure was reported to be $9 \%$ for PPV in the Melody valve trial. $^{2}$

\section{Limitations}

The limitations of our study are primarily related to its retrospective design. No attempt was made to exactly match the patients in this study to patients who qualify for PPV and patients were only matched by age and weight. For example, 1 criterion for PPV implant in the Melody valve trial was that patients needed to have a previously implanted dysfunctional RV outflow tract conduit or bioprosthetic valve. ${ }^{2}$ This was not a requirement for patients in our study cohort; however, all patients in our study cohort had an 
TABLE 3. Outcomes comparison for other published surgical pulmonary valve replacement (PVR) series

\begin{tabular}{|c|c|c|c|c|c|c|}
\hline First author & Year & Sample (n) & 30-d mortality ( $\%)$ & 5-y mortality $(\%)$ & 5-y redo-PVR $(\%)$ & $\begin{array}{c}\text { Age }(y) \text { at PVR } \\
(\text { mean } \pm \text { SD or median }[\text { range }])\end{array}$ \\
\hline Batlivala and colleagues $^{6}$ & 2012 & 254 & 1.2 & 1.9 & 3 & $16 \pm 3$ \\
\hline Chen PC and colleagues ${ }^{7}$ & 2012 & 227 & 0 & 3 & 6 & $19(0.4-58)$ \\
\hline Lee and colleagues ${ }^{8}$ & 2012 & 170 & 1.2 & 1.2 & 2.9 & $17(5-60)$ \\
\hline Jang and colleagues ${ }^{8}$ & 2012 & 131 & 0 & 0 & 3.5 & $15 \pm 7$ \\
\hline Zubairi and colleagues ${ }^{10}$ & 2011 & 169 & 0.6 & N/A & 7 & $15(0.6-49)$ \\
\hline Shinkawa and colleagues ${ }^{11}$ & 2010 & 73 & 0 & 0 & 1.3 & $17(2-64)$ \\
\hline Lim and colleagues $^{12}$ & 2004 & 58 & 2.5 & 2.5 & 12.1 & $14 \pm 10$ \\
\hline Cesnjevar and colleagues ${ }^{13}$ & 2004 & 47 & 0 & 2.1 & 6.4 & $19 \pm 12$ \\
\hline Warner and colleagues $^{14}$ & 2003 & 36 & 0 & 2.8 & 2.8 & $15 \pm 9$ \\
\hline
\end{tabular}

$S D$, Standard deviation; $N / A$, not applicable.

intervention before the surgical PVR. This was because there is no specific guideline of patient selection for PPV and decisions vary between institutions and by physician preference. Despite a majority of patients undergoing concomitant procedures in our cohort, favorable outcome with low rates of reintervention were achieved. It is fair to assume that all patients with valve deterioration would be identified when returning for further care; however, due to the retrospective nature of our study follow-up echocardiographic data describing actual functionality of the repaired conduit was not collected.

\section{CONCLUSIONS}

It is understandable that interventional cardiologists promote and patients prefer a PPV. In making a decision between PPV placement and surgical PVR, patients should be educated that surgical PVR does not confer higher procedural risk with low in-hospital and midterm follow-up mortality and reoperation rates. These outcomes provide a useful benchmark for treatment strategy comparisons.

\section{References}

1. Zahn EM, Hellenbrand WE, Lock JE, McElhinney DB. Implantation of the Melody transcatheter pulmonary valve in patients with a dysfunctional right ventricular outflow tract conduit early results from the U.S. Clinical trial. J Am Coll Cardiol. 2009;54:1722-9.

2. McElhinney DB, Hellenbrand WE, Zahn EM, Jones TK, Cheatham JP, Lock JE, et al. Short- and medium-term outcomes after transcatheter pulmonary valve placement in the expanded multicenter US Melody valve trial. Circulation. 2010;122:507-16.
3. Morales DL, Zafar F, Arrington KA, Gonzalez SM, McKenzie ED, Heinle JS, et al. Repeat sternotomy in congenital heart surgery: no longer a risk factor. Ann Thorac Surg. 2008;86:897-902.

4. McElhinney DB, Cheatham JP, Jones TK, Lock JE, Vincent JA, Zahn EM, et al. Stent fracture, valve dysfunction, and right ventricular outflow tract reintervention after transcatheter pulmonary valve implantation: patient-related and procedural risk factors in the US Melody valve trial. Circ Cardiovasc Interv. 2011;4: 602-14.

5. Gatlin SW, Kim DW, Mahle WT. Cost analysis of percutaneous pulmonary valve replacement. Am J Cardiol. 2011;108:572-4.

6. Batlivala SP, Emani S, Mayer JE, McElhinney DB. Pulmonary valve replacement function in adolescents: a comparison of bioprosthetic valves and homograft conduits. Ann Thorac Surg. 2012;93:2007-16.

7. Chen PC, Sager MS, Zurakowski D, Pigula FA, Baird CW, Mayer JE Jr, et al. Younger age and valve oversizing are predictors of structural valve deterioration after pulmonary valve replacement in patients with tetralogy of Fallot. J Thorac Cardiovasc Surg. 2012;143:352-60.

8. Lee C, Kim YM, Lee CH, Kwak JG, Park CS, Song JY, et al. Outcomes of pulmonary valve replacement in 170 patients with chronic pulmonary regurgitation after relief of right ventricular outflow tract obstruction: implications for optimal timing of pulmonary valve replacement. J Am Coll Cardiol. 2012;60:1005-14.

9. Jang W, Kim YJ, Choi K, Lim HG, Kim WH, Lee JR. Mid-term results of bioprosthetic pulmonary valve replacement in pulmonary regurgitation after tetralogy of Fallot repair. Eur J Cardiothorac Surg. 2012;42:e1-8.

10. Zubairi R, Malik S, Jaquiss RD, Imamura M, Gossett J, Morrow WR. Risk factors for prosthesis failure in pulmonary valve replacement. Ann Thorac Surg. 2011; 91:561-5.

11. Shinkawa T, Anagnostopoulos PV, Johnson NC, Watanabe N, Sapru A, Azakie A. Performance of bovine pericardial valves in the pulmonary position. Ann Thorac Surg. 2010;90:1295-300.

12. Lim C, Lee JY, Kim WH, Kim SC, Song JY, Kim SJ, et al. Early replacement of pulmonary valve after repair of tetralogy: is it really beneficial? Eur J Cardiothorac Surg. 2004;25:728-34.

13. Cesnjevar R, Harig F, Raber A, Strecker T, Fischlein T, Koch A, et al. Late pulmonary valve replacement after correction of Fallot's tetralogy. Thorac Cardiovasc Surg. 2004;52:23-8.

14. Warner KG, O’Brien PK, Rhodes J, Kaur A, Robinson DA, Payne DD. Expanding the indications for pulmonary valve replacement after repair of tetralogy of fallot. Ann Thorac Surg. 2003;76:1066-71. 